\title{
Colômbia: o divórcio entre o Estado e a nação
}

\author{
MARÍA LUJÁN BRITO \\ MARCELO CORDIVIOLA
}

A Colômbia tem atravessado, por um longo período de sua história, uma série de conflitos. Seu nome é sinônimo de violência, narcotráfico, desrespeito aos direitos humanos, deslocamento de massas populacionais, exilados, zonas controladas por poderes alternativos ao próprio Estado, ou seja, sinônimo de caos institucional. O Estado-nação tem sofrido uma ruptura. A sociedade "oscila” entre a institucionalidade estatal e o apoio às causas defendidas pelos grupos insurgentes. Ambas as alternativas distorcem a realidade pela violência que engendram em sua luta por espaços de poder; situação coadjuvada pelo narcotráfico, que se perde nessa luta e beneficia ambas as partes.

A hipótese desta nota se baseia na convicção de que, em tal competição, nenhuma das partes busca ser vitoriosa, já que o ato de ganhar implicaria custos que nenhuma delas poderia suportar.

Três elementos sustentam essa hipótese: em primeiro lugar, a sociedade não se sente identificada com o Estado, isto é, não se sente respaldada pelo marco jurídico que ele deve prover; situação que tem levado a que ela se sinta mais identificada com o discurso dos grupos insurgentes (guerrilhas) do que com seus governos oficiais. Em resumo, a ação do governo em busca da reivindicação e restabelecimento do monopólio do uso da força não está respaldada pela sociedade, tampouco é vista com bons olhos a violência exercida pelos grupos insurgentes quotidianamente nas ruas.

Em segundo lugar, o Estado busca ganhar sua posição, como já foi mencionado, mediante o aumento da violência contra a insurgência, mas sem assegurar o monopólio do uso da força, muito menos garantir a segurança aos cidadãos. Por sua vez, apesar de suas táticas de enfrentamento, a guerrilha não tem êxito em seus objetivos de poder, agregando somente mais elementos ao caos, fazendo com que suas motivações e ideais sejam vistos de maneira difusa.

Por último, quanto ao contexto internacional, em particular na América Latina, os países que se limitam com a Colômbia vêem na situação a possibilidade de que se comprometa seriamente a estabilidade democrática regional, sem outra alternativa de intervenção que não seja o Plano Colômbia, isto é, uma ajuda econômico-militar e não uma ação conjunta desde a concepção política até a metodológica, em busca de soluções para a situação. 


\section{A história da alternância de poder no Estado}

A história política colombiana se caracterizou pela alternância bipartidarista, entre o Partido Liberal e o Partido Conservador, até a última eleição presidencial, que rompeu com esse esquema a partir do atual presidente Alvaro Uribe. Entretanto, não se pode ignorar mais de cinqüenta anos de história, já que tanto as forças políticas liberais como as conservadoras propiciaram o nascimento de movimentos guerrilheiros e de forças paramilitares, bem como do narcotráfico.

No final dos anos cinqüenta, foi constituída a Frente Nacional, a partir do entendimento alcançado pelos partidos políticos tradicionais, possibilitando a inserção de um “dualismo” partidário com alternância, que permitiu a conformação de feudos dentro do próprio Estado, onde o clientelismo viveu sua época de bonança, perdendo-se nesse processo a idéia e a doutrina com a qual havia se construído o Estado.

Entretanto, nessa história de construção de uma alternativa, que no início parecia ser uma saída possível, conformou-se, ao contrário, uma aliança entre o governo e as elites dominantes que buscou impor suas idéias sobre todo o resto, engendrando um quadro de violência que retornaria periodicamente à vida colombiana.

Nesse momento da "aliança” apareceram os primeiros grupos armados, que foram influenciados pela recente Revolução Cubana e conservaram os laços

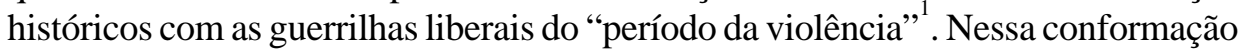
de grupos guerrilheiros estiveram presentes as Forças Armadas Revolucionárias da Colômbia (Farc), o Exército de Liberação Nacional (ELN) e outros grupos menores.

Durante décadas, desenvolveram-se negociações por diversos meios entre o Estado e a guerrilha no interesse da paz, sem nenhum êxito. Durante o governo de Andrés Pastrana (1998-2002), foi implementado um conjunto de ações que buscaram frear as causas da violência e construir a paz, com a ajuda da comunidade internacional. Seu pilar fundamental foi o Plano Colômbia, que contemplava a pacificação e desmobilização da guerrilha, a construção de um Estado moderno e a luta contra o narcotráfico. Durante esse período, ocorreram intensas negociações sem resultado algum.

Com a posse de Alvaro Uribe o conflito se agrava, pois, longe de seguir a tradição de negociação com a guerrilha, o presidente intensificou o enfrentamento por meio do Plano Colômbia, com uma forte intervenção militar-estatal, contando com a ajuda externa proveniente, principalmente, dos Estados Unidos.

\section{A estrutura do caos}

Na intrincada trama do conflito colombiano, relacionam-se diferentes atores que têm dado vida à violência existente: 1) as forças políticas tanto liberais como conservadoras e sua amarga história de lutas pelo poder; 2) os barões da droga, 
que, a partir das altas taxas de retorno dessa indústria ilegal, corromperam todo o sistema estadual, até arrastá-lo a um equilíbrio instável à beira do colapso; 3) as guerrilhas, que perderam, nesse caminho, seus "ideais" e passaram a conviver com os barões da droga para buscar, ou perder ali, seus objetivos políticos de chegar ao poder; 4) a violência comum, já inserida na vida própria da Colômbia, expressão da criminalidade habitual, que aparece agora como algo dogmático e que mantém a sociedade em um "estado de natureza"; 5) as forças paramilitares que se conformaram para impor uma certa ordem no meio do caos e terminaram transformando-se em mais um ator negativo, que contribui para o mesmo mal; 6) o Estado, inacabado em sua construção e carcomido por todos os atores, deixando os que deve proteger à sua própria sorte; 7) as Forças Armadas, a Polícia e a própria Justiça, que servem somente como barreira de contenção do mal, que tem em si inserida a violência destrutiva; e, por último, mas não menos importante, 8) a corrupção existente em todo o sistema, que coloca definitivamente em xeque qualquer instância de legalidade ou intenção de buscar um remédio para a pior calamidade vivida por esse país: a institucionalização da violência a partir do deterioramento do Estado.

\section{$O$ contexto regional}

Em relação ao contexto regional, não se pode deixar de centrar a atenção no Brasil como ator chave da região e na importância de sua vinculação com o Plano Colômbia, no que diz respeito às estratégias antinarcóticos e ao desenvolvimento alternativo de cultivos.

As estratégias antinarcóticos vinculam todos os países envolvidos não somente na cadeia de produção de entorpecentes ilícitos, como também nos circuitos de trânsito e distribuição (embora não no consumo). Para o Brasil, esse não é um problema alheio às preocupações atuais, já que o país está envolvido em diferentes níveis, que incluem fortes laços entre os grupos produtores e os traficantes. A segunda estratégia guarda estreita ligação com a Bacia Amazônica, área tida como uma “questão de Estado”. O desenvolvimento de um planejamento central, como o Sistema de Proteção da Amazônia (Sipam), combina a vigilância e a proteção, com uma forte participação de todos os setores estatais.

O narcotráfico tem instalado no Cone Sul um debate em termos de políticas públicas que implica essencialmente o redirecionamento das funções dos Estados envolvidos, comprometendo suas Forças Armadas na luta contra esse flagelo. Essa situação tem se convertido em um condicionante para o processo de tomada de decisões no interior de cada país, que carece, ao mesmo tempo, de uma visão integral do problema.

O Brasil tem buscado uma diferenciação na região com respeito às políticas intervencionistas dos Estados Unidos, expressando diretamente o respeito pelas 
decisões do governo colombiano e rechaçando qualquer tipo de intervenção externa, transformando-se em uma peça chave para a situação colombiana. Com sua política de não-intervenção, impede o respaldo para se levar a cabo integralmente qualquer política intervencionista, entendendo-se que sem sua participação e aprovação isso não seja viável.

\section{Conclusões}

Nessa "estrutura do caos", a hipótese inicial é claramente explicativa. $\mathrm{O}$ abandono da essência do Estado impõe um absolutismo único, que beneficia a partir da desordem - a quem o impulsiona, mas prejudica enormemente aos simples cidadãos. A Colômbia é um Estado com muitos feudos, onde cada príncipe delibera à vontade sobre os destinos daqueles que ali vivem, vítimas ou vassalos de seus ditames.

Ao analisar a situação, questiona-se muitas vezes por que ninguém atentou diretamente contra o sistema estatal e por que a guerrilha não toma o poder, dada sua presença em grande parte do território colombiano.

Tomar o poder significaria dar espaço a uma ação militar direta por parte do Estado, que equivaleria ao suicídio dos grupos insurgentes. Por outro lado, essa ação seria condenada pela comunidade regional, que não permitiria retrocessos democráticos, e esse cenário proporia um novo dilema, ao instaurar a problemática de como seria um narco-Estado.

De outro lado, encontra-se o Estado, para o qual o fato de impor uma ordem definitiva, atrás da busca pelo monopólio do uso da força, implicaria uma militarização que a sociedade não estaria disposta a suportar, já que esse povo tem padecido de todo tipo de transgressões sem consulta político-institucional alguma. Somado a essa situação há a impossibilidade do Estado de assegurar condições mínimas, como: "servir a comunidade, promover a prosperidade geral e garantir a efetividade dos princípios, direitos e deveres consagrados na Constituição...”.

A Colômbia, nesse novo século, coloca à América do Sul um problema paradoxal. O Estado é mais saqueado pelos atores para-estatais que entrelaçam seus objetivos com o narcotráfico, atentando contra a essência de um poder central dominante.

Sabe-se que cartéis da droga já não subjazem em solo colombiano, mas estendem-se por diferentes âmbitos sul-americanos. As guerrilhas desconhecem os limites fronteiriços, com um novo contexto de ação que dá a elas força diversificadora distinta do que tradicionalmente se conhece como "guerrilha”. Nesse contexto, o problema colombiano e os princípios de solução não virão simplesmente de ações conjuntas que permitam sustentar processos de paz como ocorreu na América Central a partir de Contadora. 
Nesse novo contexto, em que a América Latina deve formular políticas para conter e dar soluções a esse processo violento, não cabe a possibilidade de soluções que acompanhem as iniciativas emanadas pelos Estados Unidos. Nesse sentido, o Brasil tem assinalado o rumo aos Estados sul-americanos acerca do qual o problema colombiano deve ser solucionado. Marcou o "não-reconhecimento" das Farc como forças beligerantes e, dessa maneira, impulsionou uma resposta global e sul-americana. Da mesma forma, tem sugerido que os países não sigam os Estados Unidos em sua política intervencionista na região, mas, ao contrário, propõe unir esforços com vistas à paz não-conflitiva e regida pelos desígnios impulsionados pela América do Sul.

A Colômbia está constituída por uma diversidade de atores que impedem uma clara busca de soluções internas e externas; é uma rede de relações difícil de desentranhar e compreender. O país se apresenta hoje para a América como um tema central, que traz consigo muitas questões, novas pela conjunção de vários atores e, portanto, difíceis de abordar, sendo, ao mesmo tempo, apaixonantes para a análise das alternativas de política.

\section{Notas}

1 Foi o assassinato de Jorge Eliécer Gaitán, que desatou o início formal desse período, marcado pelo enfrentamento entre conservadores e liberais. Sua morte trouxe um grave descontentamento entre seus seguidores, que iniciaram logo uma revolta na capital colombiana, conhecida como “El Bogotazo".

2 Plano Colômbia, março de 2000. 